\title{
OPEN Biologically synthesized iron nanoparticles (FeNPs) from Phoenix dactylifera have anti-bacterial activities
}

\author{
Faryal Batool ${ }^{1}$, Muhammad Shahid Iqbal ${ }^{2}$, Salah-Ud-Din Khan ${ }^{3}$, Javed Khan ${ }^{4}$, Bilal Ahmed $^{5}$ \& \\ Muhammad Imran Qadir ${ }^{1 凶}$
}

Nanotechnology is a vast field of science with the most vibrant and conspicuous applications. The green synthesis approach is cost-effective, eco-friendly, and produces the most stable metal-based nanoparticles without the use of toxic chemicals. This study presents the green synthesis of iron nanoparticles (FeNPs). For biosynthesis of FeNPs, Phoenix dactylifera extract was used as a reducing agent and iron sulfate heptahydrate $\left(\mathrm{FeSO}_{4} \cdot 7 \mathrm{H}_{2} \mathrm{O}\right)$ was used as a substrate. FeNPs were characterized by different techniques including UV-Visible spectroscopy, Fourier transform infrared spectroscopy (FTIR), and nano zeta-sizer analysis. The antimicrobial activity of FeNPs synthesized by using an aqueous extract of Phoenix dactylifera was evaluated against Escherichia coli, Bacillus subtilis, Micrococcus leutus, and Klebsiella pneumoniae. A notable color change from yellow to black confirmed the synthesis of FeNPs. The sharp peak at $450 \mathrm{~nm}$ UV-Visible spectroscopy confirmed the synthesis of FeNPs. FTIR showed the presence of $\mathrm{O}-\mathrm{H}$ and $\mathrm{C}=\mathrm{C}$ stretching due to the presence of phenol and alkene functional groups. The average size of FeNPs was $6092 \mathrm{~d} . \mathrm{nm}$. The results of antimicrobial activity showed that FeNPs exhibit different potential against different bacterial strains with a maximum $25 \pm 0.360$ zone of inhibition against Escherichia coli. Thus, green synthesized FeNPs could be used as potential antimicrobial agents.

Nanotechnology is a revolutionary approach that involves the management of atoms and molecules at the nanoscale ${ }^{1}$. Nanotechnology has emerged as an exciting field of research in modern sciences and provides different types of products including nanoparticles, nanorods, or nanotubes with different dimensions. All these nano-sized products have different specific roles. They may vary according to their size and shape, chemical nature, and crystalline, amorphous, and solid-state of occurrence ${ }^{2}$. Nanoparticles have different properties in contrast to their bulk materials because of their occurrence in nanoscale ${ }^{3}$. Metallic nanoparticles are widely used in several fields including the textile industry, food industry, agriculture, health sector, and cosmetics. They also exhibit high surface area due to their extremely small size. The importance of these nanoparticles lies in the influence of their size on the physiochemical properties of any substance $e^{4,5}$.

Iron nanoparticles (FeNPs) are the tiniest particle of iron metal with a large surface area and high reactivity. They are non-toxic. FeNPs have excellent dimensional stability and also possess high thermal and electrical conductivity, high surface area, and are highly magnetic. FeNPs can oxidize immediately when exposed to water or air and produces free Fe ions. There are numerous applications of FeNPs but the most promising one includes their role in drug delivery.

There are several conventional approaches to synthesize FeNPs. Such conventional approaches like chemical and physical methods involve toxic and expensive chemicals and more use of energy. To reduce the use of chemicals and energy, the biological synthesis approach proves to be compatible, less expensive, less time-consuming, stable, and eco-friendly. Biological synthesis involves fungi, bacteria, viruses, and plants as reducing agents. Among all these sources, the plant-based green synthesis approach gains more attention due to the easy handling

${ }^{1}$ Institute of Molecular Biology and Biotechnology, Bahauddin Zakariya University, Multan, Pakistan. ${ }^{2}$ Department of Clinical Pharmacy, College of Pharmacy, Prince Sattam Bin Abdulaziz University, Al-Kharj 11942, Saudi Arabia. ${ }^{3}$ Department of Biochemistry, College of Medicine, Imam Mohammad Ibn Saud Islamic University (IMSIU), Riyadh 11432, Saudi Arabia. 'Department of Public Health, College of Health Sciences, Saudi Electronic University, Riyadh 11673, Saudi Arabia. ${ }^{5}$ Department of Clinical Pharmacology, School of Pharmacy, Nanjing Medical University, Jiangsu Province, Nanjing, People’s Republic of China. ${ }^{\bowtie}$ email: mrimranqadir@hotmail.com 


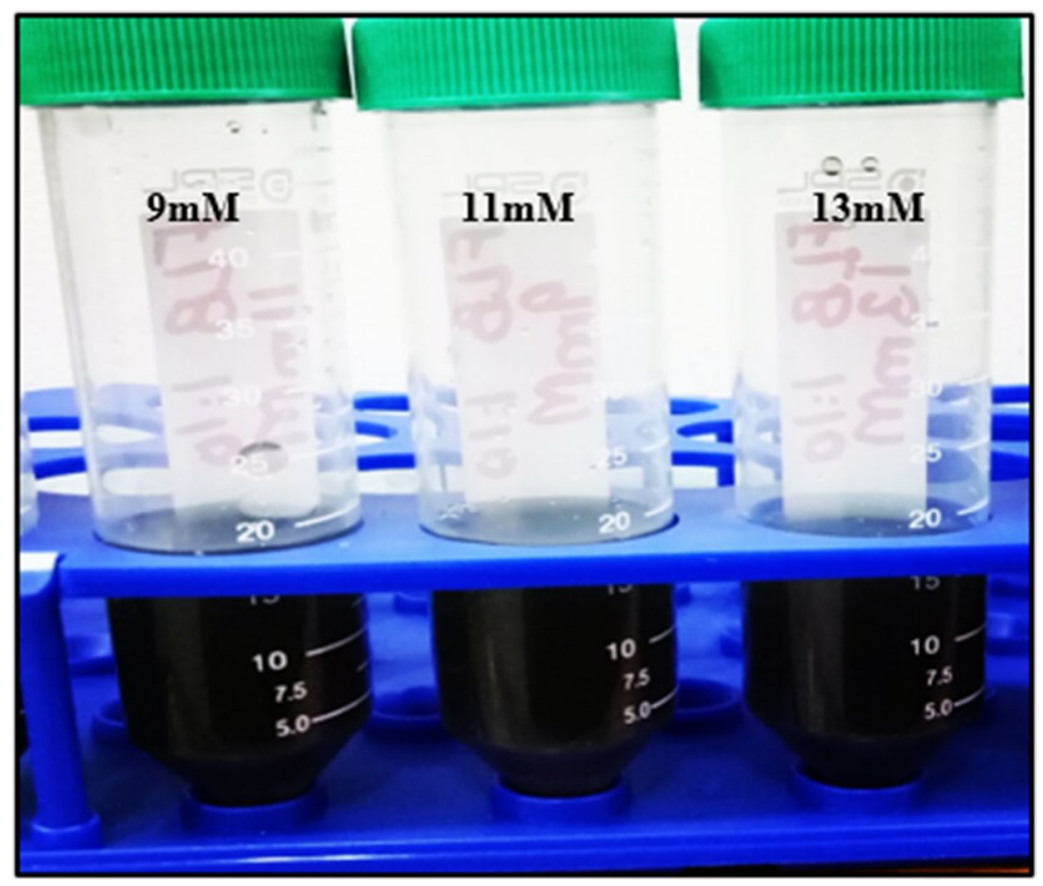

Figure 1. Iron Nanoparticles synthesized by Phoenix dactylifera leaves extracts.

of plants ${ }^{6-8}$. Green synthesis of nanoparticles using plant biomaterials include different parts of the plant-like stem, leaves, roots, fruits, and seeds. Synthesizing nanoparticles by plant materials is the most familiar, simple, and cost-effective approach ${ }^{3,9}$. Plants produce more stable nanoparticles as compared to microorganisms. Plants are naturally composed of several organic reducing compounds, enhancing the ability of plants to synthesize nanoparticles ${ }^{3,10}$. A symbiotic relationship is generated between nanotechnology and plant sciences due to the usage of plant phytochemicals in the synthesis of nanoparticles. This interrelation between plant science and nanotechnology is termed "green nanotechnology"11.

So far, several types of plants have been used to synthesized FeNPs, Phoenix dactylifera plant has gained huge medicinal importance because of its versatile phytochemical composition including flavonoids, phenolics, carotenoids, sterols, procyanidins, and anthocyanins. These components are accountable for different pharmacological activities like anti-inflammatory, anti-asthmatic, anti-diabetic, antibacterial, aphrodisiac, hepatoprotective, and nephroprotective activities ${ }^{12-15}$. It has been recognized that leaves of Phoenix dactylifera showed prominent antibacterial results as compared to the seed and fruit of the plant ${ }^{16}$. Therefore, the objective of this study was to synthesize FeNPs by green synthesis method using Phoenix dactylifera leaf extract, their characterization, and evaluation of the antimicrobial activity.

\section{Results}

FeNPs were successfully synthesized using Phoenix dactylifera extract by the green method. The color of the reaction mixture containing 1:10 of extract and $\mathrm{FeSO}_{4} \cdot 7 \mathrm{H}_{2} \mathrm{O}$ changed from yellow to black after overnight shaking at $37^{\circ} \mathrm{C}$ as shown in Fig. 1. The color change indicated that phytoconstituents of Phoenix dactylifera caused the reduction of Fe into FeNPs. This initial reduction creates a nucleation center, which leads to the accumulation of more metal ions while also incorporating the nucleation site next to it. NPs are formed as a result which becomes entrapped with biological molecules of the plant for better stability and improved morphology.

The synthesis of FeNPs was confirmed by UV-Visible analysis. The wavelength range was set at $100-800 \mathrm{~nm}$. Sharp peaks were observed at $450 \mathrm{~nm}$ which is characteristic of FeNPs. Different absorbance peaks were observed for FeNPs synthesized from different salt concentrations. Absorbance peaks keep on increasing as the concentration of salt increases from 9 to $13 \mathrm{mM}$ as shown in Fig. 2.

FTIR spectroscopy was used to identify the presence of functional groups responsible for the synthesis of FeNPs from an aqueous extract of Phoenix dactylifera ${ }^{10}$. Figure 3 represents the absorbance bands of FeNPs in the range of wave region between 1000 and $3500 \mathrm{~cm}^{-1}$. Characteristics peaks were observed at 1636.34 and $3282.19 \mathrm{~cm}^{-1}$. The band at $3282.19 \mathrm{~cm}^{-1}$ represented the $\mathrm{O}-\mathrm{H}$ stretching due to the presence of phenol or alcohol as a functional group and those $1636.34 \mathrm{~cm}^{-1}$ confirmed the $\mathrm{C}=\mathrm{C}$ stretching due to the alkene functional group.

Nano Zeta-sizer using DLS strategy was used for determining the size of green synthesized FeNPs and a graph was obtained as shown in Fig. 4. This graph shows the intensity of scattering light on the y-axis and size (diameter in nanometer) on the $\mathrm{x}$-axis. The size of the particle was obtained in the range of 950 to $3000 \mathrm{~d} . \mathrm{nm}$ with one maximum and a sharp peak at $1438 \mathrm{~d} . \mathrm{nm} / 100.0 \%$. Z-average size of FeNPs was $6092 \mathrm{~d} . \mathrm{nm}$ with PDI of 0.909 and PDI width of 5809 d.nm. 


\section{UV Visible Spectrophotometry}

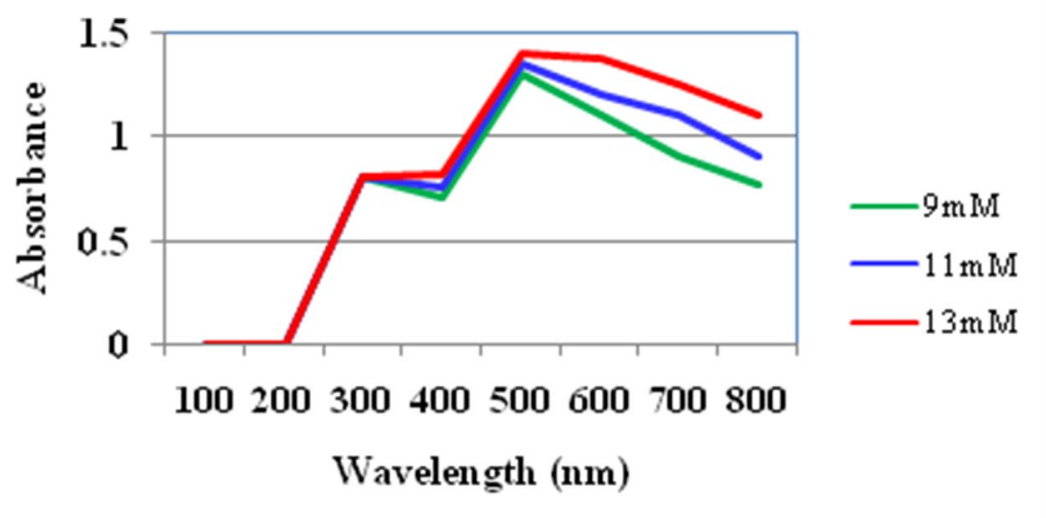

Figure 2. UV absorbance spectrum for FeNPs synthesized by Phoenix dactylifera leaves extract.

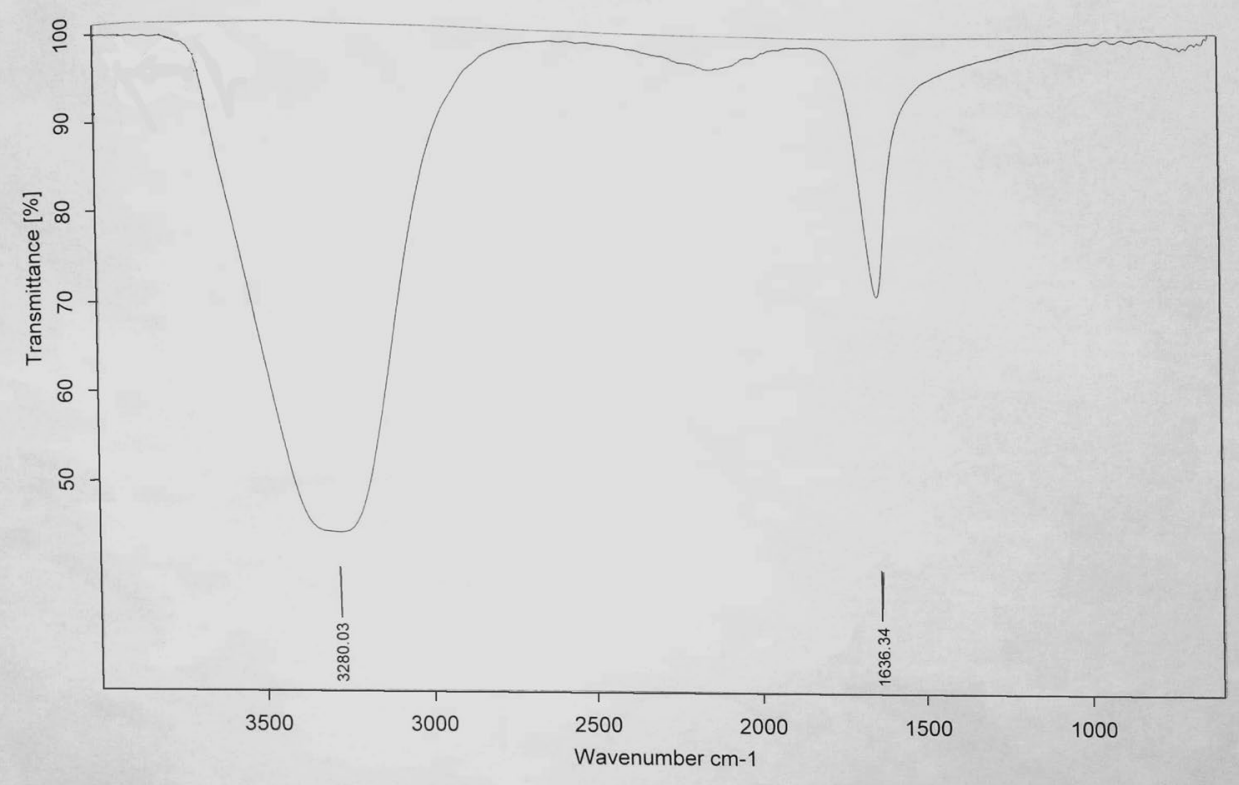

Figure 3. FTIR Spectrum for FeNPs synthesized by Phoenix dactylifera leaves extract.

The antimicrobial activity of FeNPs was evaluated by the agar well diffusion method. Zone of inhibitions for FeNPs produced by three different salt concentrations are given in Table 1 and Fig. 5A, B (Same conditions were maintained for each experiment). FeNPs synthesized by using $13 \mathrm{mM}$ salt concentration showed a maximum zone of inhibition of $25 \mathrm{~mm}$ against Klebsiella pneumonia and Escherichia coli. While the minimum zone of inhibition i.e., $13 \mathrm{~mm}$ was observed for FeNPs (synthesized from $9 \mathrm{mM}$ salt concentration) against Bacillus subtilis and Klebsiella pneumonia.

\section{Discussion}

Currently, nanotechnology is a growing field of science with the most vibrant and conspicuous applications. Several types of synthesis methods of metal nanoparticles are now mentioned in literature and practiced by researchers as well to find out new and emerging applications of nanoparticles. There are three methods used for synthesizing FeNPs; physical, chemical, and biological. The biological method involves the synthesis of NPs by living organisms specifically plants, bacteria, fungi, and algae. Synthesis of NPs by plants refers to green nanotechnology $y^{5}$.

Metallic nanoparticle synthesis by using plant biomaterials is now considered an area with extensive research ${ }^{17,18}$. Plants are naturally composed of organic reducing agents, making them more suitable and adaptive for nanoparticle synthesis ${ }^{19}$. The green synthesis approach produces nanoparticles without the elimination 


\section{Size Distribution by Intensity}

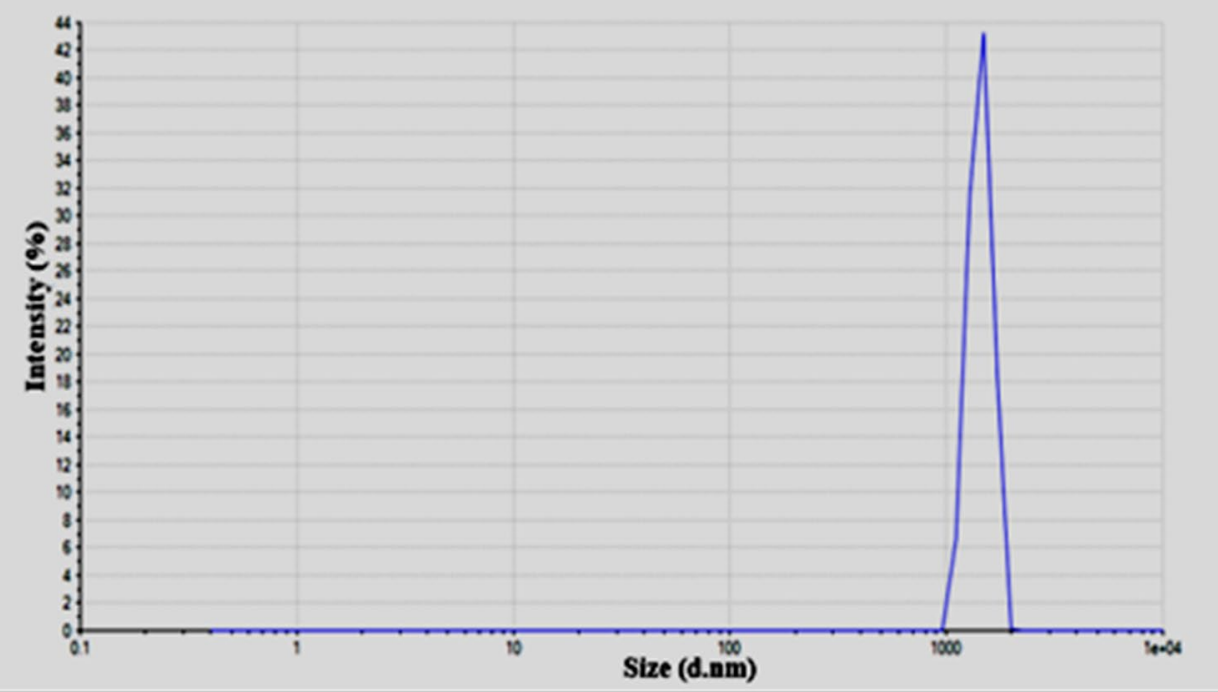

Figure 4. Size distribution by Intensity of FeNPs synthesized from Phoenix dactylifera leaves extract.

\begin{tabular}{|c|c|c|c|c|c|}
\hline $\begin{array}{l}\text { Standard drug and } \\
\text { Sample }\end{array}$ & Number of Replicates & Bacillus subtilis & Escherichia coli & Micrococcus leutus & Klebsiella pneumonia \\
\hline \multirow{4}{*}{$\begin{array}{l}\text { Standard drug (cipro- } \\
\text { floxacin) }\end{array}$} & 1 & 37.8 & 36.7 & 35.2 & 37.9 \\
\hline & 2 & 38.2 & 36.4 & 36.6 & 37.8 \\
\hline & 3 & 38 & 38 & 36.2 & 38.3 \\
\hline & Mean \pm SD & $38 \pm 0.200$ & $37 \pm 0.850$ & $36 \pm 0.721$ & $38 \pm 0.264$ \\
\hline \multirow{4}{*}{$\begin{array}{l}\text { Aqueous extract of Phoenix } \\
\text { dactylifera leaves }\end{array}$} & 1 & 12.0 & 10.0 & 10.0 & 13.2 \\
\hline & 2 & 11.0 & 10.0 & 10.0 & 10.8 \\
\hline & 3 & 10.0 & 10.0 & 10.0 & 12.0 \\
\hline & Mean \pm SD & $11 \pm 0.102$ & $10 \pm 0.250$ & $10 \pm 0.312$ & $12 \pm 0.140$ \\
\hline \multirow{4}{*}{$\begin{array}{l}9 \mathrm{mM} \\
\text { FeNPs }\end{array}$} & 1 & 12.8 & 13.8 & 0 & 13.4 \\
\hline & 2 & 13.4 & 14.2 & 0 & 12.5 \\
\hline & 3 & 12.8 & 14 & 0 & 13.1 \\
\hline & Mean \pm SD & $13 \pm 0.346$ & $14 \pm 0.200$ & $0 \pm 0$ & $13 \pm 0.458$ \\
\hline \multirow{4}{*}{$\begin{array}{l}11 \mathrm{mM} \\
\text { FeNPs }\end{array}$} & 1 & 19.6 & 23.2 & 16.4 & 21.6 \\
\hline & 2 & 19.3 & 22.5 & 17.7 & 22.3 \\
\hline & 3 & 21.1 & 23.3 & 16.9 & 22.1 \\
\hline & Mean \pm SD & $20 \pm 0.964$ & $23 \pm 0.435$ & $17 \pm 0.655$ & $22 \pm 0.360$ \\
\hline \multirow{4}{*}{$\begin{array}{l}13 \mathrm{mM} \\
\text { FeNPs }\end{array}$} & 1 & 22.7 & 24.9 & 18.8 & 25.7 \\
\hline & 2 & 23.2 & 25.4 & 19.4 & 24.8 \\
\hline & 3 & 23.1 & 24.7 & 21.8 & 24.8 \\
\hline & Mean \pm SD & $23 \pm 0.264$ & $25 \pm 0.360^{*}$ & $20 \pm 1.587$ & $25 \pm 0.519^{*}$ \\
\hline
\end{tabular}

Table 1. Zone of Inhibition of FeNPs synthesized by Phoenix dactylifera. ${ }^{*} \mathrm{p}$ value $<0.05$ indicates significant results compared to standard.

of environmental pollutants, making it a more viable and economically efficient technology ${ }^{19}$. Plants are capable of reducing metallic ions on their surface as well as different tissues. Plants with a higher capacity of reduction and accumulation of metal ions are used for metal-based nanoparticle synthesis. In the green synthesis approach, the phytocompounds present in the extract of the plant are involved in the reduction of the metal ions, they also act as stabilizers of the iron nanoparticles ${ }^{20}$. Polyphenols, terpenoids, and flavonoids in the plant act as both a reducing agent and a capping agent resulting in the production of nanoparticles i.e. zero-valent FeNPs ${ }^{21,22}$.

Several plant extracts have been given a successful trial for the synthesis of metallic nanoparticles ${ }^{19}$. Camellia sinensis, Azadirachta indica, Tridax procumbens, Passiflora tripartitavar, Syzygium cumini, Terminalia chebula, Salvia officinalis, Dodonaea viscose, Oolong tea, and Rumex acetosa extracts are reported to synthesize different types of FeNPs with different but specific applications ${ }^{23-25}$. Phoenix dactylifera is an important plant with several 
A
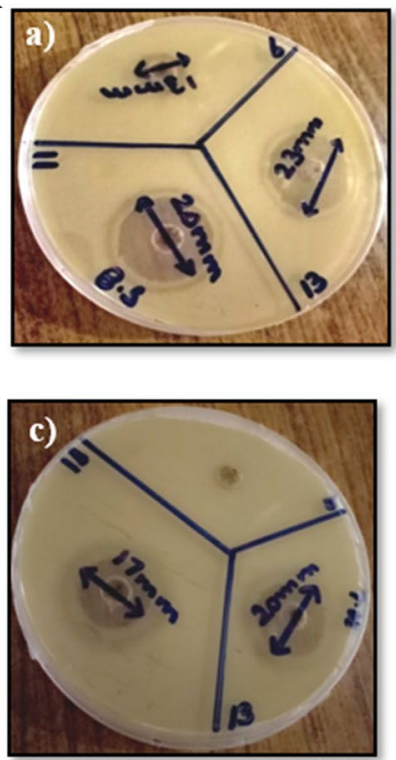
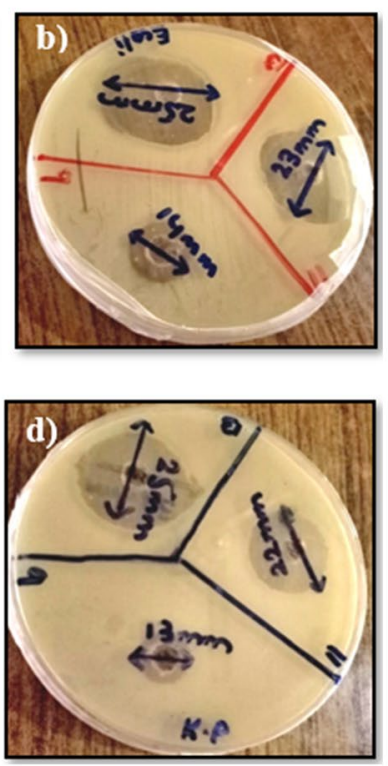

B
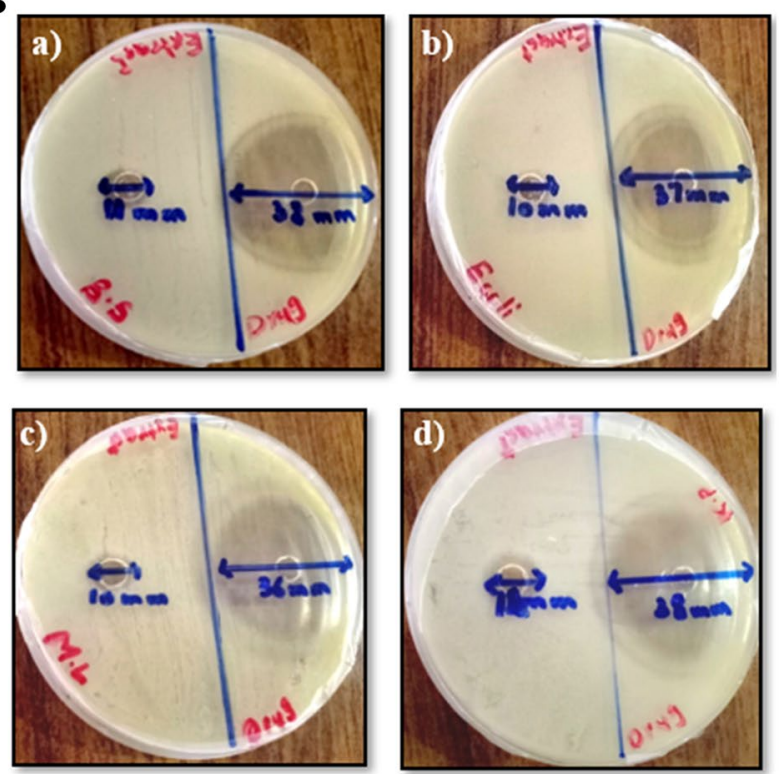

Figure 5. (A) Antimicrobial activity of synthesized FeNPs against (a) Bacillus subtilis, (b) Escherichia coli, (c) Micrococcus leutus, (d) Klebsiella pneumonia. (B) Antimicrobial activity of standard drug and extract of Phoenix dactylifera leaves against (a) Bacillus subtilis, (b) Escherichia coli, (c) Micrococcus leutus, (d) Klebsiella pneumonia.

medicinal applications. Phoenix dactylifera has been previously used for the synthesis of several other metallic nanoparticles. Such as Muhammad et al. ${ }^{26}$ synthesized silver nanoparticles by using leave extract of Phoenix dactylifera and Barani et al..$^{27}$ also used leave extract of Phoenix dactylifera to synthesize zinc oxide nanoparticles. Thus, in this study, Phoenix dactylifera was used as a source to produce FeNPs.

Green synthesis of FeNPs was confirmed by UV-Visible spectroscopy. According to one study, the UV spectrum of FeNPs synthesized by bulb extract of Murraya koenigii exhibited broad absorption peaks between 275 and $500 \mathrm{~nm}^{28}$. Similarly, FeNPs synthesized by leaf extract of Glycosmis mauritiana, absorption spectra were observed between 202 and $410 \mathrm{~nm}^{3}$. FeNPs synthesized by Spinacia oleracea also exhibited absorption peaks between the range of 400-450 nm region. Flower extract mediated FeNPs of Musa ornata give absorption peaks between 250 and $350 \mathrm{~nm}^{29}$. Tridax procumbent mediated synthesis of FeNPs when subjected to UV analysis, displayed the highest absorption peak at $450 \mathrm{~nm}^{18}$. These studies are in accordance with our results as Phoenix dactylifera mediated FeNPs showed an absorbance peak at $450 \mathrm{~nm}$.

Characterizing plant-mediated nanoparticles by FTIR spectroscopy explains the association of phytochemical components of extracts with the nanoparticle. According to the literature, terpenoids are mostly linked with nanoparticle synthesis. Terpenoids are plant-based and organic polymer which shows strong antioxidant activity. According to one study, FTIR spectra for FeNPs synthesized by leaf extract of Platanus orientalis were obtained by scanning the FeNP sample between the range of $400-4500 \mathrm{~cm}^{-1}$. Its spectrum displays stretching of the $\mathrm{C}-\mathrm{H}$ group at $2096 \mathrm{~cm}^{-1}$ and bending of $\mathrm{H}-\mathrm{C}-\mathrm{H}$ at 1315 and $1410 \mathrm{~cm}^{-1}$. C-O and $\mathrm{C}-\mathrm{C}$ stretching was observed at a range of about 1000-1450 $\left(\mathrm{cm}^{-1}\right)^{9}$. Another example includes FTIR analysis of FeNPs synthesized by flower extract of Musa ornata. FTIR analysis was performed between the range of $400-4000 \mathrm{~cm}^{-1}$. Three sharp peaks at $480.69,3383.42$, and $1634.15 \mathrm{~cm}^{-1}$ were displayed on FTIR spectra of previously mentioned example ${ }^{29}$. These studies supported our results and revealed that the presence of $\mathrm{O}-\mathrm{H}$ and $\mathrm{C}=\mathrm{O}$ bonds due to phenol/alcohol and Alkene functional groups are involved in the synthesis and stability of FeNPs from Phoenix dactylifera.

FeNPs have different sizes and morphology according to their types. According to one research study, SEM analysis of iron oxide nanoparticles exhibited the size of FeNPs in the range of 58-79 nm, while the morphology of FeNPs was spherical ${ }^{30}$. Another example includes SEM analysis of FeNPs with a diameter of $7.7 \mathrm{~nm}$ synthesized by using Passiflora foetida extract ${ }^{31}$.

Jamzad and colleagues performed an experiment where they synthesized iron oxide nanoparticles using the biogenic synthesis method. FeNP nanoparticles were synthesized using the aqueous extract of the plant Laurus nobilis. The initial characterization was done through UV-Vis spectroscopy. The synthesized nanoparticles showed the maximum absorption at the range of $285 \mathrm{~nm}$ which indicated the synthesis of FeNPs. The FTIR spectroscopy revealed several peaks of the synthesized nanoparticle sample which indicated the functional groups which were involved in the synthesis of nanoparticles and their stability. X-ray diffraction analysis confirmed that the synthesized nanoparticles were crystalline. These iron oxide nanoparticles have notable antimicrobial activity against gram-positive bacteria ${ }^{32}$.

In another research conducted by Laouini et. al., synthesis of silver and silver oxide nanoparticles was done using Phoenix dactylifera leaves extract. Various properties of the synthesized silver nanoparticles were studied. Dye degradation property and catalytic activity of the silver and the silver oxide nanoparticles were also studied in this project. UV-visible spectroscopy (UV spectroscopy), Fourier transform infrared spectroscopy (FTIR), 
X-ray diffraction study (XRD), and scanning electron microscopy (SEM) were done. The UV spectroscopy showed that the silver nanoparticles had absorption peaks at $430 \mathrm{~nm}$ which is the reported wavelength range for silver nanoparticles. The spherical shape of the silver nanoparticles was confirmed by the SEM and various functional groups which were involved in the synthesis and stability of the nanoparticles were confirmed by FTIR spectroscopy. The silver nanoparticles were crystalline and their size was about $28.66-39.40 \mathrm{~nm}$ and it was confirmed by XRD. This study reported that the synthesized nanoparticles had notable catalytic activity against the degradation of the dyes ${ }^{33}$.

According to numerous research-based studies, FeNPs have evident antimicrobial activities against bacterial cultures including Escherichia coli, Staphylococcus aureus, Salmonella enteric, Pseudomonas aeruginosa, Streptococcus pyogenes, Aeromonas hydrophila, Klebsiella pneumonia, Bacillus cereus, and Enterococcus faecalis ${ }^{17,34}$. In a study, researchers evaluated the antibacterial activity of FeNPs against Escherichia coli, Pseudomonas aeruginosa, and Staphylococcus aureus by using different ratios of $\mathrm{FeSO}_{4}$ salt and Azardirachta Indica leaf extract ${ }^{35}$. Another study reported the antibacterial activity of iron oxide nanoparticles synthesized from Punica granatum peel extract. Results of this study reported that a maximum zone of inhibition (22 \pm 0.5$)$ was observed against Pseudomonas aeruginosa ${ }^{36}$. Our results are also in accordance with these studies. These findings are consistent with the proposed mechanism of antimicrobial action of FeNPs involving particle accumulation in the cytosol. The smaller the nanoparticle, the greater the penetration and accumulation capacity of nanoparticles within the bacterial cell wall. Nanoparticles should cause the rupture of the bacterial cell membrane by which cellular content fugues take place ${ }^{37,38}$. Moreover, small-sized nanoparticles have a larger surface area which causes the conformational changes in bacterial cell DNA and as a result, causes bacterial cell death. This could also be a mechanism involved in the antibacterial potential of FeNPs ${ }^{39}$. It might explain why FeNPs have the different antibacterial potential for different types of bacteria; because gram + ive bacteria have a thick peptidoglycan membrane, there is likely a high degree of contact between organisms and nanoparticles due to their small size. Instead of a cytoplasmic membrane, gram -ive bacteria have a cytoplasmic membrane and an outer cell membrane, with only a thin film of peptidoglycan between them. It is extremely difficult for FeNPs to penetrate the thin layer in this situation ${ }^{40}$.

Another hypothesized mechanism for the antibacterial activity of FeNPs is the generation of reactive oxygen species (ROS), like hydroxyl radicals and singlet oxygen inside the bacterial cell. The phenomenon of ROS occurs due to the Fenton reaction of Fe and metabolic products e.g. hydrogen peroxide of bacterial cells ${ }^{35,41}$. ROS produce oxidative stress in bacteria cells, resulting in bacterial mortality. Though the antibacterial mechanism of action of FeNPs is not very clear, however, it is evident that these nanoparticles could act as potential antibacterial agents.

Along with prominent antimicrobial activity, FeNPs also have numerous other applications in different fields including medical, catalysis, environmental, and magnetic areas ${ }^{9,42,43}$.

\section{Conclusion}

FeNPs were successfully synthesized by a green method using Phoenix dactylifera leaf extract. Synthesis of FeNPs was confirmed by a notable color change of the sample from yellow to black and initially characterized by UV Visible Spectrophotometer with a sharp peak at $450 \mathrm{~nm}$. Further characterization of green synthesized FeNPs was done through FTIR and nano Zeta-sizer for detection of the responsible functional group of phytochemical constituents of the Phoenix dactylifera extract and size of synthesized FeNPs respectively. FTIR absorbance bands of FeNPs were observed at 1636.34 and $3282.19 \mathrm{~cm}^{-1}$. The presence of the $\mathrm{O}-\mathrm{H}$ (phenol or alcohol) functional group was confirmed by the absorbance band at $3282.19 \mathrm{~cm}^{-1}$ and the Alkene group present in the wave region $1636.34 \mathrm{~cm}^{-1}$ was also confirmed. The size of the particle using Nano Zeta-sizer was obtained in the range of 950-3000 d.nm with one maximum and sharp peak at $1438 \mathrm{~d}$. nm/100.0\%. Z-average size of FeNPs was $6092 \mathrm{~d}$. $\mathrm{nm}$ with PDI of 0.909 and PDI width of $5809 \mathrm{~d} . \mathrm{nm}$. Antimicrobial activity pf FeNPs was performed against four bacterial strains including Klebsiella pneumonia, Bacillus subtilis, Micrococcus leutus, and Escherichia coli. Maximum antimicrobial activity was observed for FeNPs (synthesized from $13 \mathrm{mM}$ salt concentration) against Escherichia coli $(25 \pm 0.360)$ and Klebsiella pneumonia (25 \pm 0.519$)$. Aqueous extract of Phoenix dactylifera offers an eco-friendly and cost-effective method to synthesize FeNPs which could be pave way for diverse applications, especially as antimicrobial agents.

\section{Materials and methods}

Collection of materials. Experimental research procedures on plants were accomplished according to the institutional guidelines of the Institute of Molecular Biology and Biotechnology, Bahauddin Zakariya University, Multan, Pakistan. Fresh leaves of Phoenix dactylifera were collected from Biopark, Bahauddin Zakariya University, Multan, Pakistan in 2019. The plant parts were cleaned with tap water and were identified by Dr. Zafar Ullah Zaffar, Taxonomist, Department of Botany, Bahauddin Zakariya University, Multan, and the specimen was deposited in the herbarium of the institute with voucher No. IMBB 1923.

Iron sulfate heptahydrate $\left(\mathrm{Fe}_{2} \mathrm{SO}_{4} \cdot 7 \mathrm{H}_{2} \mathrm{O}\right)$ was purchased from DaeJung Chemicals, Lahore, Pakistan.

Phoenix dactylifera extract preparation. $20 \mathrm{~g}$ fresh date palm tree leaves were washed thoroughly with distilled water to remove dirt particles and then dried in the laboratory for $20 \mathrm{~min}^{44}$. Leaves were chopped into small pieces by scissors and boiled in $100 \mathrm{ml}$ distilled water ${ }^{45}$. Boiling of the extract was done on a water bath for $30 \mathrm{~min}$ at $70{ }^{\circ} \mathrm{C}^{38}$. The extract was cooled at room temperature and then filtered using $125 \mathrm{~mm}$ filter paper. The color of the extract was dark yellow ${ }^{1}$. 
Preparation of salt solution. 1 molar stock solution of $\mathrm{Fe}_{2} \mathrm{SO}_{4} \cdot 7 \mathrm{H}_{2} \mathrm{O}$ was prepared in $50 \mathrm{ml}$ of distilled water. $9 \mathrm{mM}, 11 \mathrm{mM}$, and $13 \mathrm{mM}$ dilutions of stock solution were prepared ${ }^{46}$.

Synthesis of iron nanoparticles (FeNPs). Using the green synthesis method of nanoparticles, Phoenix dactylifera leaves extract was used for the reduction and capping of $\mathrm{Fe}$ ions ${ }^{47}$. 1:10 sample solutions were prepared by adding $2 \mathrm{ml}$ of extract in $20 \mathrm{ml}$ of each 9,11 , and $13 \mathrm{mM} \mathrm{Fe} \mathrm{SO}_{4} \cdot 7 \mathrm{H}_{2} \mathrm{O}$ solution at normal room temperature in a $100 \mathrm{ml}$ Erlenmeyer flask. For the preparation of different concentrations of iron salt solutions, a stock solution was prepared in $50 \mathrm{ml}$ of distilled water ${ }^{48}$. The solutions were continuously stirred for $8 \mathrm{~h}$ at $60-70{ }^{\circ} \mathrm{C}$ and then subjected to further stirring at $37^{\circ} \mathrm{C}$ for $24 \mathrm{~h}^{29,49}$.

Characterization of FeNPs. Characterization of synthesized FeNPs was conducted through the following techniques.

UV Visible Spectrophotometry. After a visible color change of the sample solutions, further confirmation of synthesis of FeNPs was done through UV Visible Spectrophotometer ${ }^{50} .1 \mathrm{ml}$ of nanoparticle sample of each concentration $(9 \mathrm{mM}, 11 \mathrm{mM}$, and $13 \mathrm{mM}$ ) was used for analysis. UV analysis of these samples was conducted after $24 \mathrm{~h}$ of incubation. Absorbance was measured through UV visible spectrophotometer at $1 \mathrm{~nm}$ resolution ${ }^{51,52}$. The spectrophotometer used for measurement of the wavelength of synthesized FeNPs was PG instrument-t 80 UV/VIS Spectrophotometer.

Fourier transform infrared spectroscopy (FTIR). FTIR is used for scanning the sample and it gives information about the relevant functional groups and stabilization of synthesized FeNPs ${ }^{53-55}$. A detector can present the resulting spectrum in the range between 4000 and $400 \mathrm{~cm}^{-1}$.

For FTIR analysis, the FeNP samples were freeze-dried into powder form and diluted in Potassium Bromide with 1:100. The resulting spectrum was obtained in the range of 1000 to $3500 \mathrm{~cm}^{-1}$ wavelength ${ }^{56}$. FTIR Spectroscopy was carried out by using Bruker Germany Alpha FTIR spectrophotometer.

Dynamic light scattering (DLS). The Zeta-sizer nano series can carry outsize measurements by using a phenomenon called Dynamic Light Scattering (DLS). The Zeta-sizer nano range of instruments can help to evaluate three significant characteristics of particles within a liquid medium. These three fundamental parameters include particle size, molecular weight, and zeta potential ${ }^{57,58}$. For operating Zeta-sizer, a sample amount of minimum of $12 \mu \mathrm{L}$ and a maximum of $3 \mathrm{ml}$ and temperature range of $15-40{ }^{\circ} \mathrm{C}$ is required ${ }^{46,59}$. This procedure was carried out by using Zetasizer Nano $\$ 90$.

Evaluation of anti-microbial activity. The antimicrobial activity of synthesized nanoparticles was assessed against four bacterial cultures including Escherichia coli, Bacillus subtilis, Micrococcus leutus, and Klebsiella pneumonia by using the agar well diffusion method. All of the mentioned bacterial cultures were locally isolated, identified, and maintained by the Institute of Molecular Biology and Biotechnology, Bahauddin Zakariya University, Multan, Pakistan. For inoculum preparation, the nutrient broth was prepared and bacterial cultures were mixed with the help of a sterilized wire loop in nutrient broth and subjected to incubation at $37^{\circ} \mathrm{C}$ for $24 \mathrm{~h}$. For the agar, well diffusion method, a metallic borer with $6 \mathrm{~mm}$ size was used for making wells and ciprofloxacin was used as a standard drug.

Statistical analysis. The true experimental research design was used for performing the experiments. SPSS ver. 22 was used for analyzing the data. $\mathrm{p}<0.05$ was considered significant.

Experimental research procedures on plants. Experimental research procedures on plants were accomplished according to the institutional guidelines of the Institute of Molecular Biology and Biotechnology, Bahauddin Zakariya University, Multan, Pakistan.

Ethical approval. Experimental organisms were not used.

\section{Data availability}

All the other data that support the findings of this study are available from the corresponding author upon request.

Received: 17 March 2021; Accepted: 30 September 2021

Published online: 11 November 2021

\section{References}

1. Kaur, G., Singh, T. \& Kumar, A. Nanotechnology: A review. Int. J. Educ. Appl. Res. 2, 50-53 (2012).

2. Alvi, G. B. et al. Biogenic selenium nanoparticles (SeNPs) from citrus fruit have anti-bacterial activities. Sci. Rep. 11, 1-11 (2021).

3. Iravani, S. Green synthesis of metal nanoparticles using plants. Green Chem. 13, 2638-2650 (2011).

4. Dreaden, E. C., Alkilany, A. M., Huang, X., Murphy, C. J. \& El-Sayed, M. A. The golden age: Gold nanoparticles for biomedicine. Chem. Soc. Rev. 41, 2740-2779 (2012).

5. Khan, I., Saeed, K. \& Khan, I. Nanoparticles: Properties, applications and toxicities. Arab. J. Chem. 12, 908-931 (2017).

6. Vasantharaj, S. et al. Synthesis of ecofriendly copper oxide nanoparticles for fabrication over textile fabrics: Characterization of antibacterial activity and dye degradation potential. J. Photochem. Photobiol. B Biol. 191, 143-149 (2019). 
7. Vasantharaj, S., Sathiyavimal, S., Senthilkumar, P., LewisOscar, F. \& Pugazhendhi, A. Biosynthesis of iron oxide nanoparticles using leaf extract of Ruellia tuberosa: Antimicrobial properties and their applications in photocatalytic degradation. J. Photochem. Photobiol. B Biol. 192, 74-82 (2019).

8. Sathiyavimal, S. et al. Green chemistry route of biosynthesized copper oxide nanoparticles using Psidium guajava leaf extract and their antibacterial activity and effective removal of industrial dyes. J. Environ. Chem. Eng. 9, 105033 (2021).

9. Saif, S., Tahir, A. \& Chen, Y. Green synthesis of iron nanoparticles and their environmental applications and implications. Nanomaterials 6, 209 (2016).

10. Kalaiarasi, R., Jayallakshmi, N. \& Venkatachalam, P. Phytosynthesis of nanoparticles and its applications. Plant Cell Biotechnol. Mol. Biol. 11, 1-16 (2010).

11. Shukla, R., Chanda, N., Katti, K. K. \& Katti, K. V. Green nanotechnology-A sustainable approach in the nanorevolution. Sustain. Prep. Met. Nanopart. Methods Appl. 19, 144 (2012).

12. Vayalil, P. K. Date fruits (Phoenix dactylifera Linn): An emerging medicinal food. Crit. Rev. Food Sci. Nutr. 52, 249-271 (2012).

13. Taleb, H., Maddocks, S. E., Morris, R. K. \& Kanekanian, A. D. Chemical characterisation and the anti-inflammatory, anti-angiogenic and antibacterial properties of date fruit (Phoenix dactylifera L.). J. Ethnopharmacol. 194, 457-468 (2016).

14. Al Harthi, S., Mavazhe, A., Al Mahroqi, H. \& Khan, S. A. Quantification of phenolic compounds, evaluation of physicochemical properties and antioxidant activity of four date (Phoenix dactylifera L.) varieties of Oman. J. Taibah Univ. Med. Sci. 10, 346-352 (2015).

15. Yasin, B. R., El-Fawal, H. A. \& Mousa, S. A. Date (Phoenix dactylifera) polyphenolics and other bioactive compounds: A traditional islamic remedy's potential in prevention of cell damage, cancer therapeutics and beyond. Int. J. Mol. Sci. 16, 30075-30090 (2015).

16. Al-Daihan, S. \& Bhat, R. S. Antibacterial activities of extracts of leaf, fruit, seed and bark of Phoenix dactylifera. Afr. J. Biotechnol. 11, 10021-10025 (2012)

17. Pankhurst, Q. A., Connolly, J., Jones, S. \& Dobson, J. Applications of magnetic nanoparticles in biomedicine. J. Phys. D Appl. Phys. 36, R167 (2003).

18. Kavitha, K. et al. Plants as green source towards synthesis of nanoparticles. Int. Res. J. Biol. Sci. 2, 66-76 (2013).

19. Mukunthan, K. \& Balaji, S. Silver nanoparticles shoot up from the root of Daucus carrota (L.). Int. J. Green Nanotechnol. 4, 54-61 (2012).

20. Herlekar, M., Barve, S. \& Kumar, R. Plant-mediated green synthesis of iron nanoparticles. J. Nanopart. 2014, 1-9 (2014).

21. Fazlzadeh, M. et al. A novel green synthesis of zero valent iron nanoparticles (NZVI) using three plant extracts and their efficient application for removal of Cr (VI) from aqueous solutions. Adv. Powder Technol. 28, 122-130 (2017)

22. Sadhasivam, S., Vinayagam, V. \& Balasubramaniyan, M. Recent advancement in biogenic synthesis of iron nanoparticles. J. Mol. Struct. 1217, $128372(2020)$.

23. Hoag, G. E. et al. Degradation of bromothymol blue by 'greener'nano-scale zero-valent iron synthesized using tea polyphenols. J. Mater. Chem. 19, 8671-8677 (2009).

24. Kumar, K. M., Mandal, B. K., Kumar, K. S., Reddy, P. S. \& Sreedhar, B. Biobased green method to synthesise palladium and iron nanoparticles using Terminalia chebula aqueous extract. Spectrochim. Acta A Mol. Biomol. Spectrosc. 102, 128-133 (2013).

25. Makarov, V. V. et al. Biosynthesis of stable iron oxide nanoparticles in aqueous extracts of Hordeum vulgare and Rumex acetosa plants. Langmuir 30, 5982-5988 (2014).

26. Rashid, M. I. et al. One-step synthesis of silver nanoparticles using Phoenix dactylifera leaves extract and their enhanced bactericidal activity. J. Mol. Liq. 223, 1114-1122 (2016).

27. Salih, A. M. et al. Biosynthesis of zinc oxide nanoparticles using Phoenix dactylifera and their effect on biomass and phytochemical compounds in Juniperus procera. Sci Rep 11, 19136 (2021).

28. Haleemkhan, A., Naseem, B. \& Vardhini, B. Synthesis of nanoparticles from plant extracts. Int. J. Mod. Chem. Appl. Sci. 2, 195-203 (2015).

29. Saranya, S., Vijayarani, K. \& Pavithra, S. Green synthesis of iron nanoparticles using aqueous extract of Musa ornata flower sheath against pathogenic bacteria. Indian J. Pharm. Sci. 79, 688-694 (2017).

30. Amutha, S. \& Sridhar, S. Green synthesis of magnetic iron oxide nanoparticle using leaves of Glycosmis mauritiana and their antibacterial activity against human pathogens. J. Innov. Pharm. Biol. Sci. 5, 22-26 (2018).

31. Suganya, D., Rajan, M. \& Ramesh, R. Green synthesis of iron oxide nanoparticles from leaf extract of Passiflora foetida and its antibacterial activity. Int. J. Curr. Res. 8, 42081-42085 (2016).

32. Jamzad, M. \& Bidkorpeh, M. K. Green synthesis of iron oxide nanoparticles by the aqueous extract of Laurus nobilis L. leaves and evaluation of the antimicrobial activity. J. Nanostruct. Chem. 10, 193-201 (2020).

33. Laouini, S., Bouafia, A. \& Tedjani, M. Catalytic activity for dye degradation and characterization of silver/silver oxide nanoparticles green synthesized by aqueous leaves extract of Phoenix dactylifera L. Res. Sq. In Press (2021).

34. Huber, D. L. Synthesis, properties, and applications of iron nanoparticles. Small 1, 482-501 (2005).

35. Devatha, C., Jagadeesh, K. \& Patil, M. Effect of Green synthesized iron nanoparticles by Azardirachta indica in different proportions on antibacterial activity. Environ. Nanotechnol. Monit. Manag. 9, 85-94 (2018).

36. Irshad, R. et al. Antibacterial activity of biochemically capped iron oxide nanoparticles: A view towards green chemistry. J. Photochem. Photobiol. B Biol. 170, 241-246 (2017).

37. Ansari, M. A. \& Asiri, S. M. M. Green synthesis, antimicrobial, antibiofilm and antitumor activities of superparamagnetic $\gamma-\mathrm{Fe}_{2} \mathrm{O}_{3}$ NPs and their molecular docking study with cell wall mannoproteins and peptidoglycan. Int. J. Biol. Macromol. 171, 44-58 (2021).

38. Kirdat, P. et al. Synthesis and characterization of ginger ( $Z$. officinale) extract mediated iron oxide nanoparticles and its antibacterial activity. Mater. Today Proc. 43, 2826-2831 (2021).

39. Thomas, M. D. et al. Too much of a good thing: Adaption to iron(II) intoxication in Escherichia coli. Evol. Med. Public Health 9 , 53-67 (2021).

40. Nwamezie, O. U. I. F. Green synthesis of iron nanoparticles using flower extract of Piliostigma thonningii and their antibacterial activity evaluation. Chem. Int. 4, 60-66 (2018).

41. Cannon, R. D. Electron Transfer Reactions (Butterworth-Heinemann, 2016).

42. Shahwan, T. et al. Green synthesis of iron nanoparticles and their application as a Fenton-like catalyst for the degradation of aqueous cationic and anionic dyes. Chem. Eng. J. 172, 258-266 (2011).

43. Stoner, E. C. \& Wohlfarth, E. A mechanism of magnetic hysteresis in heterogeneous alloys. Philos. Trans. R. Soc. Lond. Ser. A Math. Phys. Sci. 240, 599-642 (1948).

44. Sathishkumar, G. et al. Green synthesis of magnetic $\mathrm{Fe}_{3} \mathrm{O}_{4}$ nanoparticles using Couroupita guianensis Aubl. fruit extract for their antibacterial and cytotoxicity activities. Artif. Cells Nanomed. Biotechnol. 46, 589-598 (2018).

45. Qadir, M. I., Ali, M., Saleem, M. et al. Hepatoprotective activity of aqueous methanolic extract of Viola odorata against paracetamolinduced liver injury in mice. Bangladesh J. Pharmacol. 9, 198-202 (2014).

46. Edison, T. J. I. \& Sethuraman, M. Instant green synthesis of silver nanoparticles using Terminalia chebula fruit extract and evaluation of their catalytic activity on reduction of methylene blue. Process Biochem. 47, 1351-1357 (2012).

47. Murgueitio, E. et al. Green synthesis of iron nanoparticles: Application on the removal of petroleum oil from contaminated water and soils. J. Nanotechnol. 2018, 1-8 (2018).

48. Pattanayak, M. \& Nayak, P. Ecofriendly green synthesis of iron nanoparticles from various plants and spices extract. Int. J. Plant Anim. Environ. Sci. 3, 68-78 (2013). 
49. Zayed, M. F. \& Eisa, W. H. Phoenix dactylifera L. leaf extract phytosynthesized gold nanoparticles; controlled synthesis and catalytic activity. Spectrochim. Acta A Mol. Biomol. Spectrosc. 121, 238-244 (2014).

50. Devatha, C., Thalla, A. K. \& Katte, S. Y. Green synthesis of iron nanoparticles using different leaf extracts for treatment of domestic waste water. J. Clean. Prod. 139, 1425-1435 (2016).

51. Amendola, V. \& Meneghetti, M. Size evaluation of gold nanoparticles by UV-Vis spectroscopy. J. Phys. Chem. C 113, 4277-4285 (2009).

52. Becheri, A., Dürr, M., Nostro, P. L. \& Baglioni, P. Synthesis and characterization of zinc oxide nanoparticles: Application to textiles as UV-absorbers. J. Nanopart. Res. 10, 679-689 (2008).

53. Astefanei, A., Núñez, O. \& Galceran, M. T. Characterisation and determination of fullerenes: A critical review. Anal. Chim. Acta 882, 1-21 (2015)

54. Shukla, N., Liu, C., Jones, P. M. \& Weller, D. FTIR study of surfactant bonding to FePt nanoparticles. J. Magn. Magn. Mater. 266, 178-184 (2003).

55. Yang, K., Peng, H., Wen, Y. \& Li, N. Re-examination of characteristic FTIR spectrum of secondary layer in bilayer oleic acid-coated $\mathrm{Fe}_{3} \mathrm{O}_{4}$ nanoparticles. Appl. Surf. Sci. 256, 3093-3097 (2010).

56. Carabante, I., Grahn, M., Holmgren, A., Kumpiene, J. \& Hedlund, J. Adsorption of As(V) on iron oxide nanoparticle films studied by in situ ATR-FTIR spectroscopy. Colloids Surf. A Physicochem. Eng. Asp. 346, 106-113 (2009).

57. Behera, S. S., Patra, J. K., Pramanik, K., Panda, N. \& Thatoi, H. Characterization and evaluation of antibacterial activities of chemically synthesized iron oxide nanoparticles. J. Nano Sci. Eng. 2, 196-200 (2012).

58. Hinterwirth, H. et al. Comparative method evaluation for size and size-distribution analysis of gold nanoparticles. J. Sep. Sci. 36, 2952-2961 (2013).

59. Varenne, F., Makky, A., Gaucher-Delmas, M., Violleau, F. \& Vauthier, C. Multimodal dispersion of nanoparticles: A comprehensive evaluation of size distribution with 9 size measurement methods. Pharm. Res. 33, 1220-1234 (2016).

\section{Author contributions}

F.B.: Prepared the nanoparticles and performed antibacterial activities. M.S.I.: Collected materials and interpreted the data. S.D.K.: Performed Dynamic Light Scattering studies. J.K.: Performed Fourier Transform Infra-Red (FTIR) Spectroscopic studies. B.A.: Gave the idea, designed and write the manuscript. M.I.Q.: Directed and supervised the whole project.

\section{Competing interests}

The authors declare no competing interests.

\section{Additional information}

Correspondence and requests for materials should be addressed to M.I.Q.

Reprints and permissions information is available at www.nature.com/reprints.

Publisher's note Springer Nature remains neutral with regard to jurisdictional claims in published maps and institutional affiliations.

(c) (i) Open Access This article is licensed under a Creative Commons Attribution 4.0 International License, which permits use, sharing, adaptation, distribution and reproduction in any medium or format, as long as you give appropriate credit to the original author(s) and the source, provide a link to the Creative Commons licence, and indicate if changes were made. The images or other third party material in this article are included in the article's Creative Commons licence, unless indicated otherwise in a credit line to the material. If material is not included in the article's Creative Commons licence and your intended use is not permitted by statutory regulation or exceeds the permitted use, you will need to obtain permission directly from the copyright holder. To view a copy of this licence, visit http://creativecommons.org/licenses/by/4.0/.

(c) The Author(s) 2021 